\title{
Unravelling the carbohydrate specificity of MelA from Lactobacillus plantarum WCFS1: An $\alpha$-galactosidase displaying regioselective transgalactosylation
}

(i) The corrections made in this section will be reviewed and approved by journal production editor.

Paloma Delgado-Fernandez ${ }^{\mathrm{a}, 1}$, Laura Plaza-Vinuesa ${ }^{\mathrm{b}, 1}$, Oswaldo Hernandez-Hernandez ${ }^{\mathrm{a}}$, Blanca de las Rivas $^{\mathrm{b}}$, Nieves Corzo ${ }^{\mathrm{a}}{ }^{*}$ nieves.corzo@csic.es, Rosario Muñoz ${ }^{\mathrm{b}}, \mathrm{F}$. Javier Moreno ${ }^{\mathrm{a}}$

anstituto de Investigación en Ciencias de la Alimentación, CIAL (CSIC-UAM), Nicolás Cabrera 9, 28049 Madrid, Spain

bInstituto de Ciencia y Tecnología de Alimentos y Nutrición, ICTAN (CSIC), Juan de la Cierva 3, 28006 Madrid, Spain

*Corresponding author.

${ }^{1}$ These authors contributed equally to this work.

\begin{abstract}
This comprehensive work addresses, for the first time, the heterologous production, purification, biochemical characterization and carbohydrate specificity of MelA, a cold-active $\alpha$-galactosidase belonging to the Glycoside Hydrolase family 36, from the probiotic organism Lactobacillus plantarum WCFS1. The hydrolytic activity of MelA $\alpha$-galactosidase on a wide range of $p$ nitrophenyl glycoside derivatives and carbohydrates of different molecular-weights showed its high selectivity and efficiency towards the $\alpha(1 \rightarrow 6)$ glycosidic bonds involving the anomeric carbon of galactose and the C6-hydroxyl group of galactose or glucose units. MelA $\alpha$-galactosidase also presented a high regioselectivity, efficiency and diversity in accommodating donor and acceptor substrates for the synthesis of $\alpha$-GOS through transgalactosylation reactions. The catalytic mechanism of MelA for the production of $\alpha$-GOS was elucidated, revealing its great preference for the transfer of galactosyl residues to the C6-hydroxyl group of galactose units to elongate the chain of $\alpha$-GOS having either a terminal sucrose (raffinose family oligosaccharides, RFOS) or a terminal glucose (melibiose, manninotriose and verbascotetraose). Our findings indicate the feasibility of using MelA $\alpha$-galactosidase from Lactobacillus plantarum WCFS1 in the hydrolysis of RFOS and
\end{abstract}


in the efficient and versatile synthesis of $\alpha$-GOS with appealing functional properties in the context of food and nutraceutical applications.

Keywords: $\alpha$-Galactosidase; Lactobacillus plantarum WCFS1; Prebiotics

\section{Introduction}

$\alpha$-D-galactosidases ( $\alpha$-D-galactoside galactohydrolase, EC 3.2.1.22) are glycoside hydrolases (GHs) that catalyze the hydrolysis of $\alpha-1,6$ linked galactoside residues from non-reducing ends of different substrates. In view of the biotechnological and medical applications derived from their hydrolytic activity, $\alpha$-Dgalactosidases are suitable for increasing the yield of crystallized sugar [1], treating Fabry disease [2], or converting B-type blood antigens to O-type antigen [3]. In addition, transgalactosylation activity at high concentrations of substrate under adequate reaction conditions has been noticed for $\alpha$-D-galactosidases [4,5]. These enzymes can catalyze the transfer of a galactosyl unit to suitable acceptors, forming $\alpha$ galactooligosaccharides ( $\alpha$-GOS) which are a group of non-digestible oligosaccharides due to the absence of $\alpha$-D-galactosidases expressed by somatic cells in the mammalian gastrointestinal tract [6]. The backbone of $\alpha$ GOS is normally comprised by $2--10$ monosaccharide units and its chemical structure is based on sequential galactose residues with a terminal sucrose (that is, raffinose family oligosaccharides (RFOS) which includes raffinose, stachyose or verbascose) or glucose, linked predominantly with $\alpha-(1-6)$ glycosidic bonds, although $\alpha-(1-3)$ or $\alpha-(1-4)$ linkages can also be present [7].

A variety of beneficial properties has been reported for $\alpha$-GOS, such as immunostimulating ability [8] or a demonstrated prebiotic effect in vitro [9,10], in rodents [11,12] and in humans [13,14], warranting their potential use as functional food ingredients [15]. Nevertheless, some side-effects, such as abdominal discomfort, diarrhea and flatulence, have been described for RFOS due to their fermentation by anaerobic bacteria in the large intestine. In this sense, $\alpha$-D-galactosidases derived from microorganisms [16-18], plants [19] or animals can be efficiently used to hydrolyze RFOS and, consequently, to avoid these side-effects [20,21]. Particularly, microorganisms offer high potential for the production of $\alpha$-galactosidases due to their advantages such as regio- and estereoselectivity, efficiency, diversity and sustainability for the design of oligosaccharides with new properties [22]. Several probiotic bacteria like Bifidobacterium and lactic acid bacteria (LAB) as Lactobacillus are ideal candidate sources in terms of their antimicrobial activity, survival in stimulated gastric environment, viability during storage and higher growth profile. Concretely, an $\alpha$ galactosidase from Lactobacillus plantarum MTCC 5422 was efficient for the removal of RFOS [23]. Moreover, $\alpha$-galactosidases from several strains of Lactobacillus reuteri showed high transgalactosylation activity for producing $\alpha$-GOS [7,24].

Lactobacillus plantarum WCFS1 is the first strain at species level whose genome was fully sequenced [25] and is encountered in a variety of environmental and appealing niches, including some fermented products and the human intestinal tract [26]. The complete genome of L. plantarum WCFS1 was determined from a single colony originally isolated from human saliva, and a high number of genes were identified that could encode enzymes involved in the hydrolysis, synthesis or modification of carbohydrates [27]. In L. plantarum the melA gene codes for a protein classified as an $\alpha$-galactosidase belonging to the GH family 36 and involved in the 
hydrolysis of melibiose into galactose and glucose [28,29], although this protein has not been biochemically nor functionally characterized so far following its expression in Escherichia coli. The melA gene is a convenient target for single-locus mutagenesis because it is predicted to encode a nonredundant function in $L$. plantarum WCFS1, and its phenotype could be measurable both quantitatively (by hydrolysis of a chromogenic substrate) and qualitatively (by the absence of growth on melibiose as a carbon source) [29]. Apart from MelA, only a few GHs from L. plantarum having $\alpha$-glucosidase [30], $\beta$-glucosidase [31,32], $\beta$ galactosidase [33,34], $\beta$-fructofuranosidase [35] or $\alpha$-rhamnosidase [36] activities have been described up to date, according to the CAZy database (http://www.cazy.org/b125.html) [37].

In this study, we choose the model probiotic organism L. plantarum WCFS1 [38] as a suitable source to produce glycosidases, and particularly $\alpha$-galactosidases, with appealing applications as described above. In order to confirm that the annotation of the melA gene (lp_3485 locus) is correct, in the present study we address the heterologous production of MelA in Escherichia coli, and its subsequent purification and biochemical characterization. The carbohydrate specificity of MelA is, then, determined by assessing its hydrolytic activity on a wide range of $p$-nitrophenyl derivatives and carbohydrates, as well as its $\alpha$ transgalactosylation activity for the synthesis of functional oligosaccharides like $\alpha$-GOS, whose use is increasingly promoted because of their health benefits.

\section{Materials and methods}

\subsection{Bacterial strains, plasmids and enzymes}

L. plantarum WCFS1 was kindly provided by Prof. M. Kleerebezem (Wageningen University \& Research, The Netherlands). E. coli DH10B and E. coli BL21 (DE3) were used as transformation and expression hosts in the pURI3-Cter vector, respectively [39]. The E. coli strains were cultured in Luria-Bertani (LB) medium at $37{ }^{\circ} \mathrm{C}$ and shaking at $140 \mathrm{rpm}$. When required, ampicillin was added to the medium at a concentration of $100 \mathrm{mg} \mathrm{L}^{-1}$.

\subsection{Chemical and reagents}

The substrates used in this study are listed in Table S1 (Supplementary Material). The complex mixture called AlphaGOS $^{\circledast}$ is composed of $3.8 \%$ melibiose, $43.6 \%$ manninotriose and $49.5 \%$ verbascotetraose, in dry matter.

\subsection{Production and purification of L. plantarum MelA}

The melA (lp_3485) gene from L. plantarum WCFS1 was PCR-amplified by Advantage HD DNA $\begin{array}{lllll}\text { polymerase } \quad(\mathrm{TaKaRa}) & \text { by } & \text { using } & \text { primers } & 1699\end{array}$

GCTATTAATGATGATGATGATGATGgtccttagccttgaagtaatgtac) (the nucleotides pairing the expression vector sequence are indicated in italics, and the nucleotides pairing the melA gene sequence are written in lowercase letters). Purified PCR product was inserted into the pURI3-Cter vector using a restriction enzyme- and ligation-free cloning strategy [39]. This vector produces recombinant protein having a six-histidine affinity tag in their C-termini. E. coli DH10B cells were transformed, recombinant plasmids were isolated, and those 
containing the correct insert were identified by DNA sequencing, and then transformed into E. coli BL21 (DE3) cells for expression.

E. coli BL21 (DE3) was transformed with pURI3-Cter-MelA recombinant plasmid. E. coli cells were grown in $\mathrm{LB}$ medium containing $100 \mathrm{mg} \mathrm{L}^{-1}$ ampicillin until an optical density at $600 \mathrm{~nm}$ of 0.4 was reached and then induced by adding isopropyl- $\beta$-D-thiogalactopyranoside (IPTG) at $0.4 \mathrm{mM}$ final concentration. Following induction, the cells were grown at $22{ }^{\circ} \mathrm{C}$ for $18 \mathrm{~h}$ and collected by centrifugation $\left(8_{2} 000 \mathrm{~g}, 15 \mathrm{~min}, 4{ }^{\circ} \mathrm{C}\right)$. The cells were resuspended in phosphate buffer $(50 \mathrm{mM}, \mathrm{pH} 7)$ containing $300 \mathrm{mM} \mathrm{NaCl}$. Crude extracts were prepared by French press lysis of the cell suspension. The insoluble fraction of the lysate was removed by centrifugation at $47,000 \mathrm{~g}$ for $40 \mathrm{~min}$ at $4{ }^{\circ} \mathrm{C}$, and the supernatant was filtered through a $0.45 \mu \mathrm{m}$ pore-size filter and then applied to a Talon Superflow resin (Clontech) equilibrated in phosphate buffer (50 mM, pH 7) containing $300 \mathrm{mM} \mathrm{NaCl}$ and $10 \mathrm{mM}$ imidazole. The bound enzyme was eluted using $150 \mathrm{mM}$ imidazole in the same buffer. The purity of the enzyme was determined by SDS-PAGE in Tris-glycine buffer. Fractions containing the His6-tagged MelA were pooled and dialyzed against $50 \mathrm{mM}$ sodium phosphate buffer, $300 \mathrm{mM}$ $\mathrm{NaCl}$, pH 7 at $4{ }^{\circ} \mathrm{C}$ using dialysis membranes (OrDial D35-MWCO 3,500, Orange Scientific, Braine-l'Alleud, Belgium) of $3.5 \mathrm{kDa}$ pore diameter. MelA was analyzed for glycosyl hydrolase activity. The amino acid sequence of MelA (UniProtKB code: F9UUF1) can be found at https://www.ncbi.nlm.nih.gov/protein/WP 011 $\underline{102184.1 .}$.

\subsection{Determination of MelA glycosidase activities}

\subsubsection{Hydrolytic activity of MelA on p-nitrophenyl glycoside derivatives}

The hydrolytic activity of MelA $\alpha$-galactosidase from L. plantarum WCFS1 was determined by using a library of $24 p$ NP-glycoside derivatives (Table S1). A stock solution of each $p$ NP-glycoside was prepared in water. The standard conditions chosen for the assay were $4 \mu \mathrm{g}$ of MelA in $50 \mathrm{mM}$ MOPS buffer $\mathrm{pH} 7.0$ containing $20 \mathrm{mM} \mathrm{NaCl}$ and $1 \mathrm{mM} \mathrm{DTT}$ at $30{ }^{\circ} \mathrm{C}$ for $10 \mathrm{~min}$. MelA protein $(4 \mu \mathrm{g})$ was added to a pre-warmed reaction mix including the substrate $(75 \mu \mathrm{l})$. The assay was performed in a 96-well Flat Bottom plate (Sarstedt) where each well contains a different substrate $(10 \mathrm{mM})$. The reaction was stopped by the addition of a reaction volume $(75 \mu \mathrm{l})$ of sodium carbonate $1 \mathrm{M}$ at $\mathrm{pH}$ 9.0. Hydrolysis of each $p \mathrm{NP}$-glycoside derivative was colorimetrically measured by liberation of $p$-nitrophenolate $(\mathrm{pNP})$ at $420 \mathrm{~nm}$ using an extinction coefficient of $\varepsilon=9310 \mathrm{M}^{-1} \mathrm{~cm}^{-1}$ in a microplate spectrophotometer PowerWave HT (Bio-Tek, USA) by using Gene 5 version 2.06 software. Blanks without enzyme for spontaneous hydrolysis of the tested substrates were carried out and data were collected in triplicate and the average activities were quantified. One unit (U) of MelA activity was defined as the amount of enzyme required to release $1 \mu \mathrm{mol}$ of $p \mathrm{NF}$ per minute at saturated $p$-NFgalactopyranoside concentration, at $30^{\circ} \mathrm{C}$ in $50 \mathrm{mM}$ MOPS buffer $\mathrm{pH} 7.0$ containing $20 \mathrm{mM} \mathrm{NaCl}$.

\subsubsection{Hydrolytic activity of MelA on carbohydrates}

The hydrolytic activity of MelA was tested using $59.3 \mathrm{U}$ in $1 \mathrm{~mL}$ of reaction on different carbohydrates (sixteen di-, three tri-, two tetrasaccharides and a commercial mixture of $\alpha$-GOS (AlphaGOS ${ }^{\circledR}$ ) comprised by one tri- and one tetrasaccharide) dissolved at $200 \mathrm{~g} \mathrm{~L}^{-1}$ in $50 \mathrm{mM}$ of MOPS buffer supplemented with $20 \mathrm{mM}$ of $\mathrm{NaCl}(\mathrm{pH}=7)$ at $22{ }^{\circ} \mathrm{C}$ (Table $\left.\mathrm{S} 1\right)$. In the case of galactotetraose, 2-fucosyl-lactose, isomaltose, nigerose 
and maltulose the concentration was $0.5 \mathrm{~g} \mathrm{~L}^{-1}$ and, in the case of planteose, the concentration was $2 \mathrm{~g} \mathrm{~L}^{-1}$. The reactions were checked by GC-FID at $24 \mathrm{~h}$. For those substrates that were hydrolyzed by MelA, additional reactions were carried out by taking aliquots at suitable time intervals (i.e., 0, 2, 4, 8, 24 and 48 h). The enzymatic reactions were carried out by triplicate and stopped by heating at $100{ }^{\circ} \mathrm{C}$ for $5 \mathrm{~min}$.

\subsubsection{Transgalactosylation activity of MelA on selected carbohydrates.}

The transgalactosylation activity of MelA was also carried out at $22{ }^{\circ} \mathrm{C}$ in $50 \mathrm{mM}$ of MOPS buffer supplemented with $20 \mathrm{mM}$ of $\mathrm{NaCl}(\mathrm{pH}=7)$ using melibiose, raffinose, stachyose and AlphaGOS ${ }^{\circledast}$ at a concentration of $400 \mathrm{~g} \mathrm{~L}^{-1}$ and, in the case of melibiose an additional concentration of $800 \mathrm{~g} \mathrm{~L}^{-1}$ was also tested. Reactions using galactose at $400 \mathrm{~g} \mathrm{~L}^{-1}$ were also assessed to observe the capability of MelA to directly transfer galactosyl units and produce $\alpha$-GOS. The reactions were monitored by GC-FID after taking aliquots from the reaction mixture at time intervals of $0,1,2,4,6,8$ and $24 \mathrm{~h}$. The enzymatic reactions were stopped by heating at $100^{\circ} \mathrm{C}$ for $5 \mathrm{~min}$.

\subsection{Biochemical and kinetic properties of MelA}

The properties of MelA were determined using $p \mathrm{NP}-\alpha-\mathrm{D}$-galactopyranoside as substrate $(1 \mathrm{mM}$ final concentration) under the standard conditions previously described. The effects of $\mathrm{pH}$ and temperature on the hydrolytic activity of MelA on $p \mathrm{NP}-\alpha$-D-galactopyranoside were studied. The optimal $\mathrm{pH}$ was determined by using citrate ( $\mathrm{pH}$ 3), acetic acid-sodium acetate ( $\mathrm{pH} 4-6)$, MOPS ( $\mathrm{pH} 6.5$ and 7) and Tris-HCl (pH 8) buffers $(50 \mathrm{mM})$. The optimal temperature was assayed by incubating purified MelA $\alpha$-galactosidase in $50 \mathrm{mM}$ MOPS buffer $\mathrm{pH} 7.0$ containing $20 \mathrm{mM} \mathrm{NaCl}, 1 \mathrm{mM}$ DTT at different temperatures $(4,10,22,30,37,45$, and $65^{\circ} \mathrm{C}$ ). For temperature stability measurements, MelA $\alpha$-galactosidase was incubated in $50 \mathrm{mM}$ MOPS buffer pH 7.0 containing $20 \mathrm{mM} \mathrm{NaCl}, 1 \mathrm{mM}$ DTT at 22, 30, 37, 45, and $65^{\circ} \mathrm{C}$ for $30 \mathrm{~min}$ and 1, 2, 4, 6, and $20 \mathrm{~h}$. Aliquots were withdrawn at these incubation times to test the remaining activity at standard conditions. The non-heated enzyme was considered as control (100\%). The analyses were performed in triplicate.

MelA kinetics were studied by using $0.2 \mu \mathrm{g}$ MelA and $p$ NP- $\alpha$-D-galactopyranoside as substrate at $30{ }^{\circ} \mathrm{C}$ in $50 \mathrm{mM}$ MOPS buffer pH 7.0 containing $20 \mathrm{mM} \mathrm{NaCl} . K_{\mathrm{m}}$ and $V_{\max }$ values were determined by nonlinear regression analysis fitting to Michaelis-Menten curves of formation rates of $p \mathrm{NP}$ as a function of the concentration of substrates from 0 to $20 \mathrm{mM}$ by using the software SigmaPlot version 13.0. The analyses were performed in triplicate.

To study the effect of metal ions, detergents, reductants, and inhibitors on $\alpha$-galactosidase activity, MelA was incubated in the presence of different additives at a final concentration of $1 \mathrm{mM}$ for 5 min at room temperature. Then, $p$ NP- $\alpha$-D-galactopyranoside was added, and the reaction mixture was incubated under standard conditions. The residual hydrolytic activity was measured after the incubation of purified enzymes with each additive. The analysed additives were $\mathrm{KCl}, \mathrm{CaCl}_{2}, \mathrm{HgCl}_{2}, \mathrm{ZnCl}_{2}, \mathrm{CuCl}_{2}, \mathrm{NiCl}_{2}, \mathrm{FeCl}_{2}, \mathrm{MnCl}_{2}$, Triton-X-100, Tween 20, Tween 80, SDS, urea, DMSO, cysteine, $\beta$-mercaptoethanol, PMSF, DEPC and EDTA. Hydrolytic activity measured in the absence of any additive was taken as control (100\%). Experiments were done in triplicate. 


\subsection{Gas chromatography with a flame ionization detector (GC-FID)}

The carbohydrate composition of the reaction mixtures was determined by GC-FID in an Agilent Technologies 7820A Gas Chromatograph (Agilent Technologies, Wilmington, DE, EEUU) equipped with a flame ionization detector (FID). Carbohydrates were analyzed as trimethyl silylated oximes (TMSO) following the method of Sanz, Villamiel and Martínez-Castro [40] using a fused silica capillary column DB-5HT, bonded, crosslinked phase (5\% phenyl-methylpolysiloxane; $15 \mathrm{~m} \times 0.32 \mathrm{~mm}$ i.d., $0.10 \mu \mathrm{m}$ film thickness) (J\&W Scientific, Folson, California, USA). The oven temperature was initially $150{ }^{\circ} \mathrm{C}$ increasing at a rate of $3{ }^{\circ} \mathrm{C} / \mathrm{min}$ to $380{ }^{\circ} \mathrm{C}$ and held this temperature during $76 \mathrm{~min}$. The injector and detector temperatures were at $280{ }^{\circ} \mathrm{C}$ and $385^{\circ} \mathrm{C}$, respectively. Injections were carried out in split mode (1:20) using nitrogen as carrier gas at a flow rate of $1 \mathrm{~mL} / \mathrm{min}$. Data acquisition and integration were performed using Agilent ChemStation software (Wilmington, DE, USA). Quantification of each sugar was performed by internal standard calibration using phenyl- $\beta$-glucoside $(0.5 \mathrm{mg} / \mathrm{mL})$. Mixture of standard solutions of glucose, galactose, fructose, lactose, raffinose and nystose were prepared over the expected concentration range to calculate the response factors of each sugar. Identification of $\alpha$-GOS disaccharides was performed by comparing the retention times (Rt) with standard $\alpha$-1,6-galactobiose $(\alpha-\mathrm{D}-\mathrm{Gal}-(1 \rightarrow 6)-\alpha-\mathrm{D}-\mathrm{Gal})$.

\section{Results and discussion}

\subsection{Biochemical characterization of MelA from L. plantarum WCFS1}

LAB have long been used as starters in food fermentation where they exert technologically important functions on raw agricultural products. The knowledge acquired on the metabolism of these bacteria opens the way to new applications, as the production of health-beneficial compounds such as prebiotic oligosaccharides. Genes encoding $\alpha$-galactosidases are present in the genome of most lactobacilli [41], and proteins having $\alpha$ galactosidase activity have been characterized in some of them, including Lactobacillus plantarum [42-44].

The melA gene from L. plantarum ATCC 8014 was previously expressed in E. coli and the $\alpha$-galactosidase activity of the encoded protein was demonstrated [28]. However, the MelA $\alpha$-galactosidase was neither purified nor biochemically characterized. L. plantarum WCFS1 possesses a MelA protein whose amino acid sequence is $99.86 \%$ identical to MelA from L. plantarum ATCC 8014. Both 738-amino acid residues proteins are identical except in the residue 672 where a conservative change Leu to Phe appeared (data not shown). The melA (lp_3485) gene from L. plantarum WCFS1 was cloned into the pURI3-Cter expression vector, and the recombinant plasmid obtained was transformed into E. coli BL21 (DE3). Cell extracts were used to detect the presence of overproduced proteins. SDS-PAGE analysis showed that there was one major band protein, approximately of $80 \mathrm{kDa}$, consistent with the theoretical molecular weight expected for MelA. The recombinant protein was observed as a single band on SDS-PAGE (Fig. 1, lane 4). Routinely, about $13.5 \mathrm{mg}$ of purified protein from $1 \mathrm{~L}$ culture was obtained.

\section{Fig. 1}




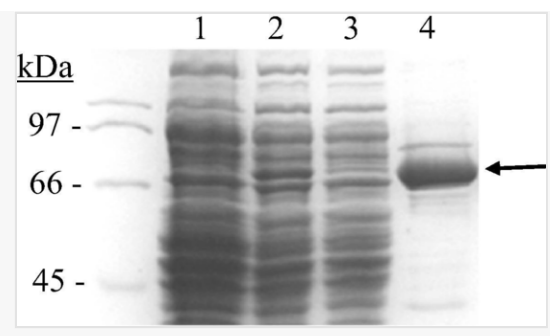

Purification of MelA $\alpha$-galactosidase from L. plantarum WCFS1. SDS-PAGE analysis of soluble cell extracts of IPTG-induced E. coli BL21 (DE3) (pURI3-Cter) (lane 1), E. coli BL21 (DE3) (pURI3-Cter-MelA) (lane 2), flowthrough (lane 3) and MelA protein eluted after affinity resin (lane 4). The gel was stained with Coomassie blue. Molecular mass markers are located on the left (SDSPAGE Standards, Bio-Rad).

The MelA protein purified by the affinity resin was biochemically characterized. Substrate specificity was determined using 24_p -nitrophenyl-linked carbohydrates of various types of $\alpha$ - or $\beta$ - linkages (Table S1). The enzyme was only active for $p$ NP- $\alpha$-D-galactopyranoside, indicating clearly its $\alpha$-galactosidase activity (624 U $\mathrm{mg}^{-1}$ ). As compared to $\alpha$-galactosidases from other LAB, the specific activity showed by MelA is remarkably higher than the activity exhibited by $\alpha$-galactosidases fs $2 w 3 z 0 m$ from Carnobacterium piscicola (2.3 U $\mathrm{mg}^{-1}$ ) [45], and Lactobacillus curvatus (5.71 $\left.\mathrm{U} \mathrm{mg}^{-1}\right)$ [46].

The influence of $\mathrm{pH}$ on MelA $\alpha$-galactosidase activity was studied at $30{ }^{\circ} \mathrm{C}$ (Fig. 2a). The enzyme showed its maximal activity at the $\mathrm{pH}$ range from 4.0 to 6.5 . This result is in agreement with the optimal $\mathrm{pH}$ exhibited by $\alpha$-galactosidases from $\mathrm{LAB}$, which varies from a $\mathrm{pH}$ close to neutral to an acidic $\mathrm{pH}$. Similar to MelA, Lactobacillus curvatus $\alpha$-galactosidase exhibited its optimal $\mathrm{pH}$ at 6.5 [46], however, the optimal $\mathrm{pH}$ of $L$. reuteri and L. fermentum $\alpha$-galactosidases were more acidic, being around 4.8 [7,47]. 

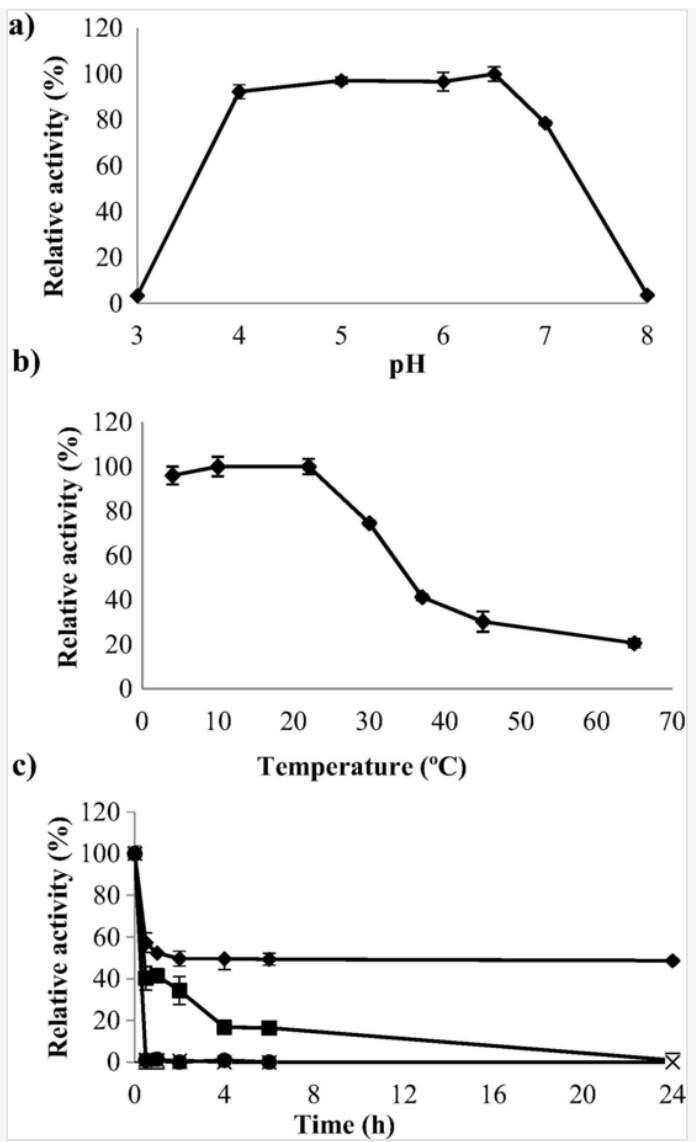

Biochemical properties of MelA $\alpha$-galactosidase. (a) MelA pH activity profile. (b) MelA temperature activity profile. (c) MelA thermal stability after incubation at $22^{\circ} \mathrm{C}(\bullet), 30^{\circ} \mathrm{C}(\boldsymbol{\bullet}), 37^{\circ} \mathrm{C}(\boldsymbol{\Delta}), 45^{\circ} \mathrm{C}(\times)$ and $65^{\circ} \mathrm{C}(\bullet)$ in MOPS buffer $(50 \mathrm{mM}, 20 \mathrm{mM}$ $\mathrm{NaCl}, 1 \mathrm{mM}$ DTT, pH 7) at indicated times. The mean value and standard error are shown $(\mathrm{n}=3)$. The percentage of residual activity was calculated by comparing to the non-incubated enzyme.

In relation to temperature, MelA is a cold-active $\alpha$-galactosidase because, from the temperatures assayed, its maximal activity was at 4,10 and $22{ }^{\circ} \mathrm{C}$ (Fig. 2b). When incubation temperature increased, MelA activity decreased. At 30 and $37^{\circ} \mathrm{C}$, MelA exhibited only 75 and $40 \%$ of its maximal activity, respectively. As far as we known, this is the first cold-active $\alpha$-galactosidase described in lactic acid bacteria. $\alpha$-Galactosidases from L. reuteri [7] and L. curvatus [46] exhibited optimal temperatures ranging from 30 to $37{ }^{\circ} \mathrm{C}$. In contrast to MelA $\alpha$-galactosidase from L. plantarum, L. fermentum possesses a thermostable MelA enzyme which showed optimal temperature at $50{ }^{\circ} \mathrm{C}$ [47]. The protein sequence of L. plantarum MelA is only $36.3 \%$ identical to MelA from L. fermentum; this amino acid sequence variability could explain the different thermal behaviour of both MelA proteins. Moreover, [Instruction: In pdf version there is an incomplete line (last line of third paragraph) from

"Moreover, L. plantarum ...."

to the next line:

MelA....

Is it possible to fill in the line? 
]L. plantarum MelA is a thermolabile enzyme, when it was preincubated at different temperatures only at $22{ }^{\circ} \mathrm{C}$ its relative activity remained around $50 \%$ throughout the $24 \mathrm{~h}$ of incubation (Fig. 2c). Among the $\alpha$ galactosidases from LAB, L. plantarum MelA is the most thermolabile enzyme, since L. curvatus $\alpha$ -

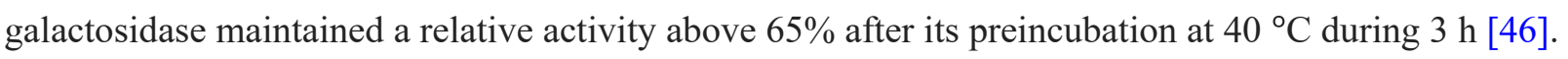

The effect of several metal ions, surfactants, reductants, and inhibitors on L. plantarum MelA activity is shown in Fig. 3. Enzymatic activity was increased $145 \%$ and $139 \%$ by $\mathrm{Mn}^{2+}$ and $\mathrm{Fe}^{2+}$ ions, respectively. In good agreement with our results, the presence of these two metal ions also increased the activity of L. reuteri $\alpha$-galactosidase [48]. In addition to these metal ions, protease inhibitors DEPC and EDTA, and the detergents Tween 20, Triton-X-100 also increased MelA activity around 40\%. These additives could activate MelA due to protein conformational changes, to a depletion of inhibitory cations, or to their surfactant effect [49]. In contrast, $\mathrm{Hg}^{2+}$ and $\mathrm{Cu}^{2+}$ greatly inhibited MelA activity to 3 and $9 \%$, respectively.

\section{Fig. 3}

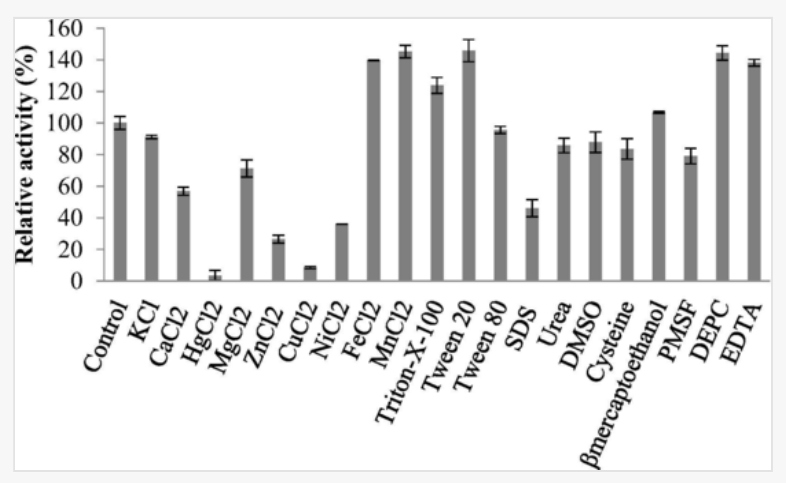

Effect of additives at $1 \mathrm{mM}$ on L. plantarum WCFS1 MelA $\alpha$-galactosidase relative activity. The activity of MelA in the absence of additives was defined as $100 \%$. The mean value and standard error are shown $(n=3)$.

Kinetic studies performed in the conditions described previously, indicated that L. plantarum MelA for $p$ NP$\alpha$-D-galactopyranoside showed a $K_{\mathrm{m}} 0.65 \pm 0.07 \mathrm{mM}$, and $V_{\max } 0.1247 \pm 0.0018 \mu \mathrm{mol} \mathrm{min}{ }^{-1}\left(624 \mathrm{U} \mathrm{mg}^{-1}\right)$ values. From these data, the $K_{\text {cat }}$ and catalytic efficacy $\left(K_{\text {cat }} / K_{\mathrm{m}}\right)$ were calculated, being the $K_{\text {cat }}$ $52125 \pm 0.0018 \mathrm{~min}^{-1}$ and the catalytic efficacy $\left(K_{\text {cat }} / K_{\mathrm{m}}\right) 80328 \pm 8405 \mathrm{mM}^{-1} \mathrm{~min}^{-1}$. This catalytic efficacy is low as compared to a Bacillus stearothermophilus $\alpha$-galactosidase which had a $K_{\text {cat }} / K_{\mathrm{m}}$ of $2.6 \times 10^{5} \mathrm{mM}^{-1} \min ^{-1}[50]$.

\subsection{Hydrolytic activity of MelA on carbohydrates}

The hydrolytic activity of MelA was tested on sixteen disaccharides, including lactose, sucrose and maltose and some of their isomers among others, being melibiose (Gal- $\alpha(1 \rightarrow 6)$-Glc) the only hydrolyzed disaccharide (peak 6 in Fig. 4a). These results pointed out the high selectivity of L. plantarum MelA and also confirmed the melA gene's annotation as a gene encoding a $\alpha$-galactosidase (EC 3.2.1.22) involved in the hydrolysis of melibiose into galactose and glucose [29]. 

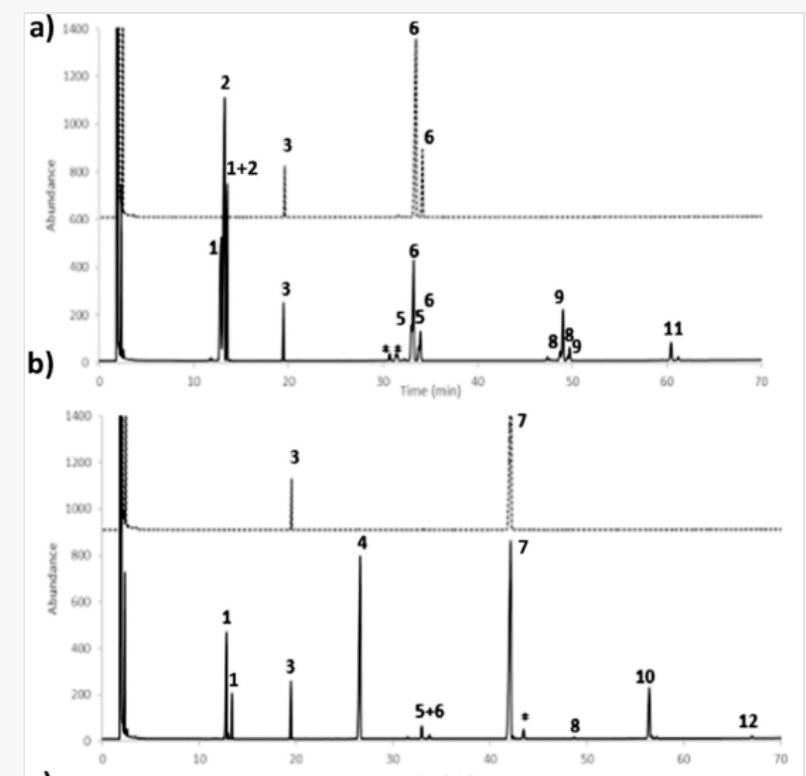

c)

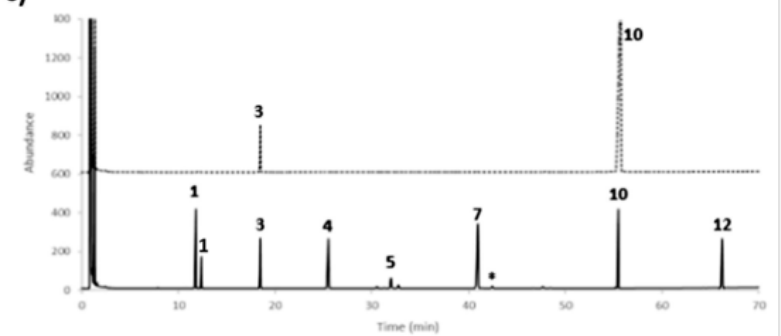

d)

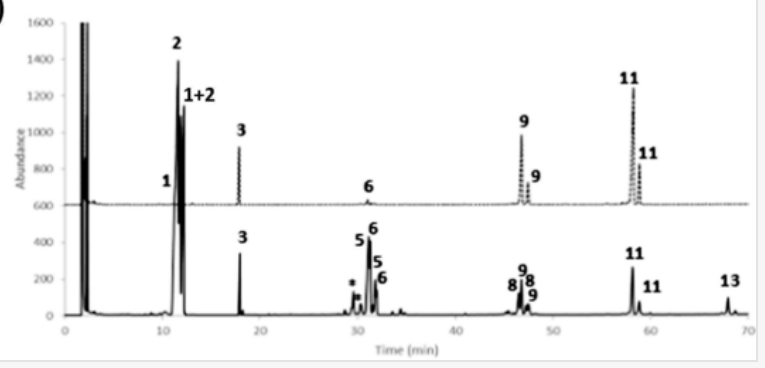

GC-FID profiles resulting from the hydrolysis of melibiose (a), raffinose (b), stachyose (c) and AlphaGOS ${ }^{\bowtie}$ (d) at $200 \mathrm{~g} \mathrm{~L}^{-1}$ at $0 \mathrm{~h}$ (dashed line) and $8 \mathrm{~h}$ (solid line) catalyzed by Lactobacillus plantarum WCFS1 MelA. Peaks identification: 1, galactose; 2 , glucose; 3, internal standard; 4, sucrose; 5, $\alpha$-1,6-galactobiose; 6 , melibiose; 7, raffinose; 8, $\alpha$-1,6-galactotriose; 9, manninotriose; 10, stachyose; 11, verbascotetraose; 12, verbascose; 13, verbascopentaose; *unknown $\alpha$-galactooligosaccharides.

The only trisaccharide hydrolyzed by L. plantarum MelA was raffinose $(\mathrm{Gal}-\alpha(1 \rightarrow 6)-\mathrm{Glc}-\alpha(1 \leftrightarrow 2) \beta$-Fru, peak 7 in Fig. 4b) which was broken at the melibiose moiety, thus, releasing sucrose $($ Glc- $\alpha(1 \leftrightarrow 2) \beta$-Fru, peak 4 in Fig. 4b) and galactose (peak 1 in Fig. 4b), whereas planteose (Gal- $\alpha(1 \rightarrow 6)$-Fru- $\beta(2 \leftrightarrow 1) \alpha-G l c)$ and 2fucosyl-lactose (Fuc- $\alpha(1 \rightarrow 2)$-Gal- $\beta(1 \rightarrow 4)$ Glc) remained unaltered upon the enzymatic reaction (data not shown). Therefore, MelA $\alpha$-galactosidase has the ability to efficiently hydrolyze the $\alpha(1 \rightarrow 6)$ bond linking a galactose unit located at the non-reducing end with glucose but not with fructose.

In order to gain more knowledge on the carbohydrate specificity of L. plantarum MelA, two tetrasaccharides as stachyose (Gal- $\alpha(1 \rightarrow 6)$-Gal- $\alpha(1 \rightarrow 6)$-Glc- $\alpha(1 \leftrightarrow 4) \beta$-Fru, peak 10 in Fig. 4c) and a galactotetraose[Instruction: Section 3.2. third paragraph last line: 
In pdf versiion appear in a line :

a galactote-

it must be corrected

] $(\mathrm{Gal}-\alpha(1 \rightarrow 3)-\mathrm{Gal}-\beta(1 \rightarrow 4)-\mathrm{Gal}-\alpha(1 \rightarrow 3)-\mathrm{Gal})$, as well as a commercial mixture of $\alpha$-GOS having a terminal glucose instead of sucrose (i.e., AlphaGOS ${ }^{\circledR}$ which are mainly comprised by manninotriose (Gal$\alpha(1 \rightarrow 6)$-Gal- $\alpha(1 \rightarrow 6)$-Glc, peak 9 in Fig. $4 d)$ and verbascotetraose (Gal- $\alpha(1 \rightarrow 6)$-Gal- $\alpha(1 \rightarrow 6)$-Gal$\alpha(1 \rightarrow 6)$-Glc, peak 11 in Fig. $4 d)$ were subjected to hydrolytic incubation with MelA $\alpha$-galactosidase. The efficient hydrolysis of either stachyose, by releasing mainly raffinose, sucrose and galactose (Fig. 4c), or AlphaGOS ${ }^{\circledR}$, by releasing mainly galactose and glucose (peak 2 in Fig. 4d), revealed that L. plantarum MelA also readily hydrolyzed $\alpha(1 \rightarrow 6)$ bonds linking consecutive galactose units from non-reducing ends.

In contrast, the assayed galactotetraose, which lacks $\alpha(1 \rightarrow 6)$ linkages, was hardly hydrolyzed (data not shown), reinforcing the high selectivity of MelA $\alpha$-galactosidase towards the $\alpha(1 \rightarrow 6)$ glycosidic bonds involving the anomeric carbon of galactose and the C6-hydroxyl group of galactose or glucose units.

Therefore, only four out of twenty two tested carbohydrates were hydrolyzed by MelA $\alpha$-galactosidase at a starting substrate concentration of $200 \mathrm{~g} \mathrm{~L}^{-1}$, being $\alpha$-GOS having either a terminal glucose (melibiose and AlphaGOS $^{\circledR}$ ) or a terminal sucrose (raffinose and stachyose) the positive substrates. Remarkably, these four hydrolysis reactions were highly efficient and yielded a percentage of degradation $\geq 93 \%$ in weight respect to the initial amount of substrate after $48 \mathrm{~h}$ of enzymatic reaction.

Lastly, in addition to the carbohydrates derived from the hydrolytic activity, new peak(s) eluting at longer retention times than the starting substrates and, consequently, corresponding to chain-elongated carbohydrates, could be detected during the hydrolysis of melibiose (see peaks 8, 9 and 11 in Fig. 4a), raffinose (peaks 8, 10 and 12 and an unknown minor trisaccharide marked with an asterisk in Fig. 4b), stachyose (peak 12 in Fig. 4c) and AlphaGOS ${ }^{\circledR}$ (peak 13 in Fig. 4d). This fact could be attributed to the transgalactosylation activity of MelA. Therefore, further experiments using higher starting concentrations of these carbohydrates were warranted and are reported in the next section.

\subsection{Transgalactosylation activity of $L$. plantarum MelA on selected carbohydrates.}

The substrate concentration is one of the critical factors coming into play when optimizing the oligosaccharide production during transglycosylation reactions catalyzed by GHs. Normally, the reduction of water concentration through the increase in total dissolved carbohydrates in the reaction favors the transglycosylation activity over the hydrolytic capacity of GHs [51,52]. Therefore, two additional initial concentrations of melibiose, that is 400 and $800 \mathrm{~g} \mathrm{~L}^{-1}$, and one $\left(400 \mathrm{~g} \mathrm{~L}^{-1}\right)$ of raffinose, stachyose, AlphaGOS ${ }^{\circledR}$ or galactose were tested for exploring the transgalactosylation activity of MelA $\alpha$-galactosidase.

\subsubsection{Synthesis of $\alpha$-GOS from galactose}


In reactions using galactose at $400 \mathrm{~g} \mathrm{~L}^{-1}$, no synthetic products were observed, in agreement with Tzortis, Jay, Baillon, Gibson and Rastall [24], who used solutions of $60--80 \%$ of galactose in the presence of an $\alpha$ galactosidase from Lactobacillus reuteri NCIMB 41152. In contrast, Yamashita, Hashimoto, Fujita, Okada, Mori and Kitahata [53] reported high yields of $\alpha$-GOS by an $\alpha$-galactosidase from fungal origin (i.e., Aspergillus niger) using supersaturated solutions of galactose $(90 \%)$ at $60{ }^{\circ} \mathrm{C}$. In our case, the use of supersaturated solutions of galactose was unworkable because the optimum temperature of L. plantarum MelA $\left(22^{\circ} \mathrm{C}\right)$ affected considerably the solubility of the monosaccharide in the reaction buffer (data not shown).

\subsubsection{Synthesis of $\alpha$-GOS from melibiose}

Melibiose was also efficiently hydrolyzed after $24 \mathrm{~h}$ by MelA $\alpha$-galactosidase at higher concentrations, since $83.6 \%$ and $80.5 \%$ of starting melibiose at 400 and $800 \mathrm{~g} \mathrm{~L}^{-1}$ respectively, was hydrolyzed (Fig. 5a and c), reinforcing, thus, the fact that melibiose is an excellent donor substrate for MelA $\alpha$-galactosidase. Moreover, regardless of the starting concentration of melibiose, the main transgalactosylated product was manninotriose $($ Gal- $\alpha(1 \rightarrow 6)-G a l-\alpha(1 \rightarrow 6)-G l c)$ (Fig. $5 b$ and d) as a result of the transfer of the galactosyl residue released from the hydrolysis of melibiose to the C6-hydroxyl group of the galactose unit of melibiose, indicating that melibiose has the capacity to act both as donor and acceptor of galactosyl moieties. The transgalactosylation activity of L. plantarum MelA was also supported by the fact that glucose content was also higher than galactose levels throughout the enzymatic reaction (Fig. 5a and c). Likewise, three additional $\alpha$-GOS compounds were observed although at a much lesser extent (around 4-fold lower) than that of manninotriose, and they were identified as i) $\alpha$-1,6-galactobiose (Gal- $\alpha(1 \rightarrow 6)$-Gal); ii) $\alpha$-1,6-galactotriose (Gal- $\alpha(1 \rightarrow 6)$ Gal- $\alpha(1 \rightarrow 6)-G a l)$; and iii) verbascotetraose $(\mathrm{Gal}-\alpha(1 \rightarrow 6)-G a l-\alpha(1 \rightarrow 6)-G a l-\alpha(1 \rightarrow 6)-G l c)$ whose synthesis was due to the ability of manninotriose to also act as acceptor of galactosyl residues (Fig. 5b and d). In consequence, MelA $\alpha$-galactosidase displayed a great regioselectivity as the only formed glycosidic linkage was the $\alpha(1 \rightarrow 6)$, and manninotriose alone accounted for around two thirds of the total $\alpha$-GOS products formed upon the enzymatic reaction.

\section{Fig. 5}



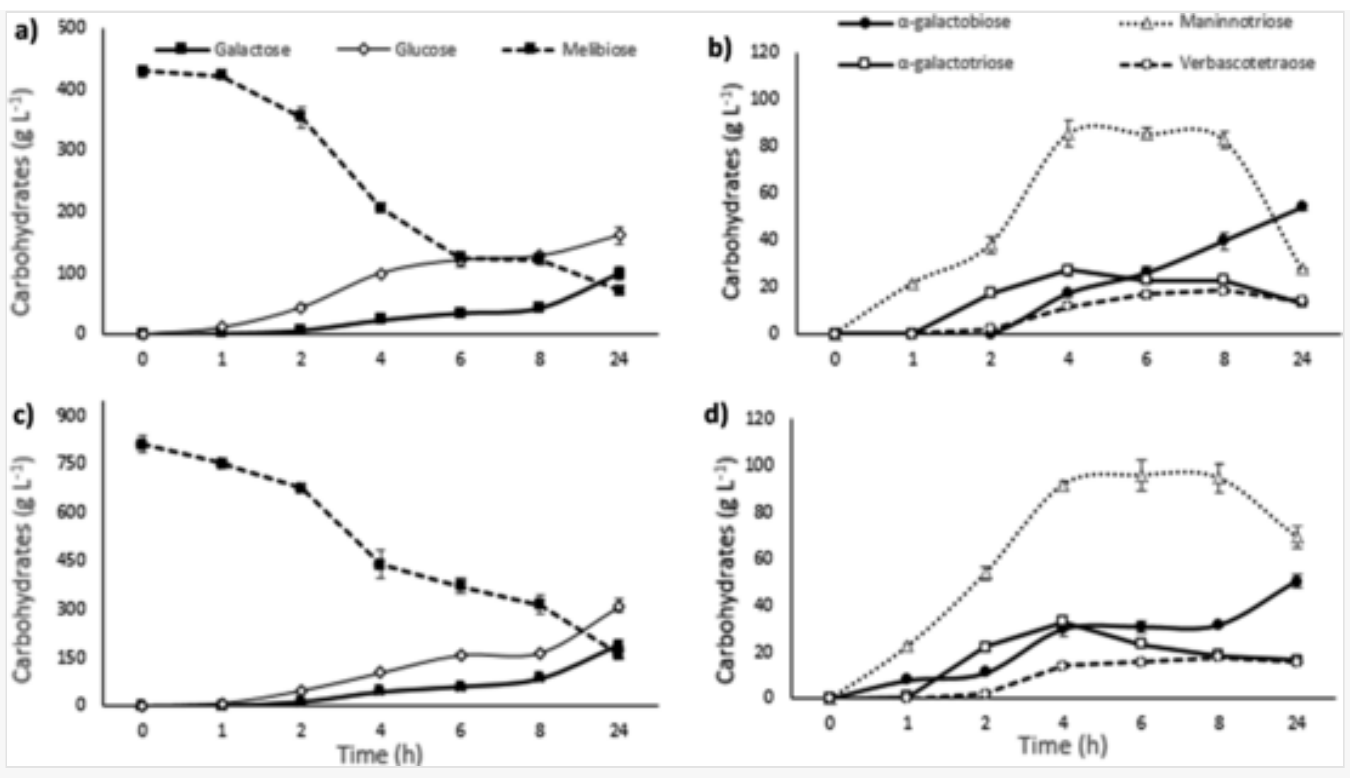

Concentration of monosaccharides, melibiose and formed $\alpha$-galactooligosaccharides upon transgalactosylation reaction catalyzed by Lactobacillus plantarum WCFS1 MelA $\alpha$-galactosidase using melibiose at $400 \mathrm{~g} \mathrm{~L}^{-1}$ (a and b) and $800 \mathrm{~g} \mathrm{~L}^{-1}$ (c and d), as starting substrate. Vertical errors represented standard deviations $(\mathrm{n}=3)$.

Overall, the synthesis of $\alpha$-GOS from melibiose was steadily increased during the first $4 \mathrm{~h}$ of reaction and then achieved a plateau until $8 \mathrm{~h}$, followed by a decrease until the end of the reaction $(24 \mathrm{~h})$. The only exception to this behavior was the disaccharide $\alpha-1,6$-galactobiose which exhibited a constant increase that was sharper between 8 and $24 \mathrm{~h}$ of reaction, suggesting that the formation of $\alpha$-1,6-galactobiose can be also driven, especially from the eighth hour of the reaction, by the hydrolysis of the rest of transfer products. This trend was observed either by using 400 (Fig. 5b) or $800 \mathrm{~g} \mathrm{~L}^{-1}$ (Fig. 5d) of starting melibiose.

Table 1 summarizes the quantitative data of the transfer products formed upon transgalactosylation reaction catalyzed by L. plantarum MelA using melibiose at different concentrations $\left(200,400\right.$, or $\left.800 \mathrm{~g} \mathrm{~L}^{-1}\right)$. The increase in starting melibiose concentration from 200 to $400 \mathrm{~g} \mathrm{~L}^{-1}$ substantially promoted the synthesis of $\alpha$ GOS, whereas the maximum concentration of total $\alpha$-GOS remained fairly constant when the melibiose concentration was increased up to $800 \mathrm{~g} \mathrm{~L}^{-1}$. In consequence, the highest yield in $\alpha$-GOS, i.e. $38.0 \%$, was obtained by using $40 \%$ of starting melibiose. Tzortzis, Jay, Baillon, Gibson and Rastall [24] reported a lower maximum yield (26\%) of $\alpha$-GOS from melibiose and did not find substantial differences in the corresponding yields when melibiose was used at $200 \mathrm{~g} \mathrm{~L}^{-1}$ or at $700 \mathrm{~g} \mathrm{~L}^{-1}$ using an $\alpha$-galactosidase from Lactobacillus reuteri NCIMB 41152. Furthermore, Wang, Black, Curtis and Gänzle [7] also demonstrated the transferase activity of an $\alpha$-galactosidase from Lactobacillus reuteri 100-23 and Lactobacillus reuteri 100-16 when melibiose was present at $600 \mathrm{~g} \mathrm{~L}^{-1}$, although no data on yields were reported.

(i) The presentation of Tables and the formatting of text in the online proof do not match the final output, though the data is the same. To preview the actual presentation, view the Proof. 
Production and yield of $\alpha$-GOS upon transgalactosylation reaction catalyzed by Lactobacillus plantarum WCFS1 MelA $\alpha$ galactosidase using melibiose, raffinose, stachyose and AlphaGOS ${ }^{\circledast}$ at different initial concentrations $\left(200,400\right.$, or $\left.^{800} \mathrm{~g} \mathrm{~L}^{-1}\right)$.

\begin{tabular}{|c|c|c|c|}
\hline & & $\alpha$-GOS & \\
\hline Starting substrates & Concentration $\left(\mathrm{g} \mathrm{L}^{-1}\right)$ & Maximum concentration $\left(\mathrm{g} \mathrm{L}^{-1}\right)$ & Yield $(\%)^{b}$ \\
\hline \multirow[t]{3}{*}{ Melibiose } & 200 & $59.6(4 \mathrm{~h})^{\mathrm{a}}$ & 28.0 \\
\hline & 400 & $162.9(8 \mathrm{~h})$ & 38.0 \\
\hline & 800 & $168.3(4 \mathrm{~h})$ & 20.8 \\
\hline \multirow[t]{2}{*}{ Raffinose } & 200 & $42.4(8 \mathrm{~h})$ & 22.6 \\
\hline & 400 & $103.3(8 \mathrm{~h})$ & 25.3 \\
\hline \multirow[t]{2}{*}{ Stachyose } & 200 & $30.4(24 \mathrm{~h})$ & 15.4 \\
\hline & 400 & $88.6(8 \mathrm{~h})$ & 20.7 \\
\hline \multirow[t]{2}{*}{ AlphaGOS $^{\circledast}$} & 200 & $39.0(4 \mathrm{~h})$ & 20.9 \\
\hline & 400 & $114.7(24 \mathrm{~h})$ & 30.5 \\
\hline
\end{tabular}

\section{Table Footnotes}

${ }^{a}$ Reaction time at the maximum concentration of transfer products.

${ }^{\mathrm{b}}$ Yield ( $\mathrm{g}$ transfer products/100 $\mathrm{g}$ starting substrate) represents the maximum mass of transfer products obtained during the synthesis per unit mass of initial substrate.

\subsubsection{Synthesis of $\alpha$-GOS from raffinose}

Raffinose at $400 \mathrm{~g} \mathrm{~L}^{-1}$ was also efficiently hydrolyzed (that is, only $15.6 \%$ of starting raffinose remained intact after $24 \mathrm{~h}$ of enzymatic reaction) by L. plantarum MelA to galactose and sucrose (Fig. 6a), revealing to be an efficient donor of galactosyl residues for MelA $\alpha$-galactosidase. In good agreement with the mechanism described above for the formation of manninotriose from melibiose, L. plantarum MelA mainly transferred galactose moieties at the C-6 hydroxyl group of the galactosyl residue of raffinose, producing high amounts of stachyose and whose maximum formation $\left(79.7 \mathrm{~g} \mathrm{~L}^{-1}\right)$ was obtained at $4 \mathrm{~h}$ of enzymatic reaction (Fig. 6b). Moreover, the formation of stachyose was even more predominant than in the case of manninotriose from melibiose, since $86.4 \%$ of the transfer products obtained from $400 \mathrm{~g} \mathrm{~L}^{-1}$ of raffinose at $4 \mathrm{~h}$ of reaction corresponded exclusively to stachyose. The rest of $\alpha$-GOS compounds was comprised by the minor presence of: (i) the pentasaccharide verbascose (due to the transgalactosylation of stachyose) and whose maximum formation was $9.0 \mathrm{~g} \mathrm{~L}^{-1}$ at $8 \mathrm{~h}$; (ii) $\alpha$-1,6-galactotriose (whose maximum formation of $2.5 \mathrm{~g}^{-1} \mathrm{~L}^{-1}$ was at 
$24 \mathrm{~h}$ ); and (iii) $\alpha$-1,6-galactobiose (maximum formation of $22.6 \mathrm{~g} \mathrm{~L}^{-1}$ at $24 \mathrm{~h}$ ); (iv) as well as an unknown trisaccharide that might correspond to an isomer of raffinose. Stachyose concentration started to decrease from the fourth hour of reaction whereas the decrease in verbascose was observed from the eight hour. In contrast, the remaining three minor $\alpha$-GOS compounds increased during the whole enzymatic reaction (Fig. 6b). Wang, Black, Curtis and Gänzle [7] reported the synthesis of four $\alpha$-GOS compounds when raffinose was present at $300 \mathrm{~g} \mathrm{~L}^{-1}$ using an $\alpha$-galactosidase from a strain of Lactobacillus reuteri. Those products included not only stachyose but also another tetrasaccharide and two trisaccharides following the transfer of galactosyl residues through $\alpha(1 \rightarrow 3)$ and $\alpha(1 \rightarrow 4)$ linkages.

\section{Fig. 6}
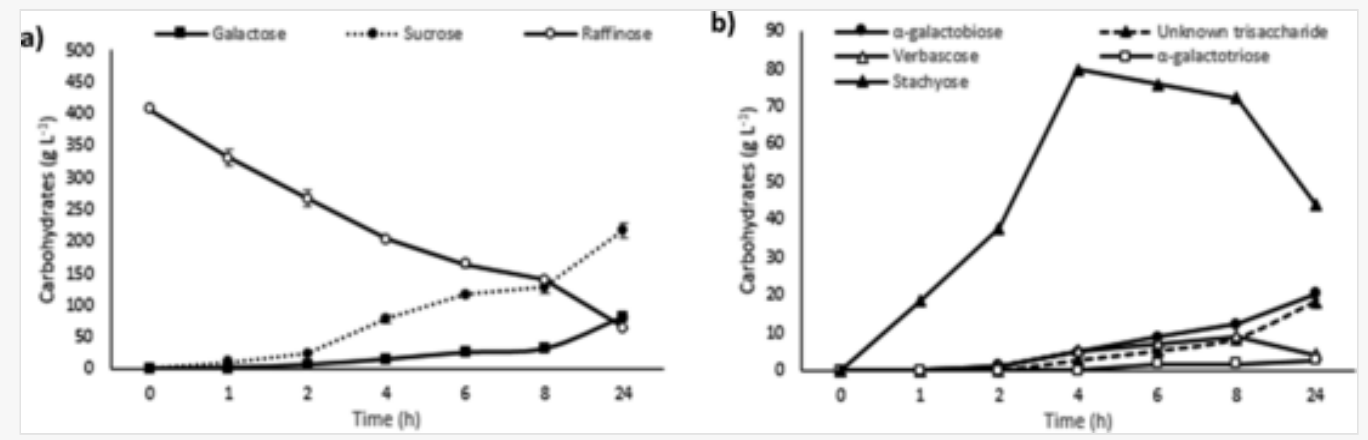

Concentration of galactose, sucrose, raffinose (a) and formed $\alpha$-galactooligosaccharides (b) upon transgalactosylation reaction catalyzed by Lactobacillus plantarum WCFS1 MelA $\alpha$-galactosidase using raffinose at $400 \mathrm{~g} \mathrm{~L}^{-1}$ as starting substrate. Vertical errors represented standard deviations $(\mathrm{n}=3)$.

Overall, the increase of the starting raffinose from 200 to $400 \mathrm{~g} \mathrm{~L}^{-1}$ led to an increase of 2.4-fold both in the maximum formation of stachyose and in the formation of total $\alpha$-GOS whose maximum yield was $25.3 \%$ ( Table 1). Likewise, this increase substantially shortened the reaction time needed to reach the maximum levels in stachyose (from 8 to 4 h). Tzortis, Jay, Baillon, Gibson and Rastall [24], using an $\alpha$-galactosidase from $L$. reuteri, reported a maximum yield of $18 \%$ for the synthesis of $\alpha$-GOS from raffinose.

\subsubsection{Synthesis of $\alpha$-GOS from stachyose}

Stachyose (Gal- $\alpha(1 \rightarrow 6)$-Gal- $\alpha(1 \rightarrow 6)$-Glc- $\alpha(1 \leftrightarrow 2) \beta$-Fru) at $400 \mathrm{~g} \mathrm{~L}^{-1}$ was also an efficient donor of galactosyl residues following its hydrolysis by releasing galactose and raffinose which was, in turn, further hydrolyzed to give rise to sucrose and galactose as shown in Fig. 7a. Thus, 87.6\% of stachyose was hydrolyzed after $24 \mathrm{~h}$ of enzymatic reaction. In addition, the higher formation of raffinose than that of sucrose observed during the first $8 \mathrm{~h}$ of reaction confirmed that L. plantarum MelA is an exo-alpha-galactosidase by catalyzing the hydrolysis of galactosyl residues from non-reducing ends. 

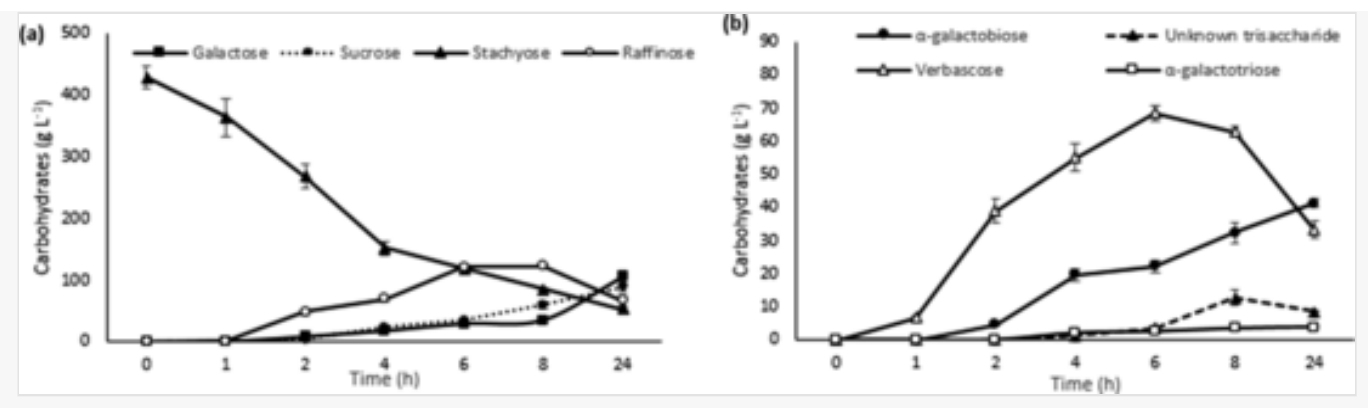

Concentration of galactose, sucrose, raffinose and stachyose (a) and formed $\alpha$-galactooligosaccharides (b) upon transgalactosylation reaction catalyzed by Lactobacillus plantarum WCFS1 MelA $\alpha$-galactosidase using stachyose at $400 \mathrm{~g} \mathrm{~L}^{-1}$ as starting substrate. Vertical errors represented standard deviations $(\mathrm{n}=3)$.

Concerning the transfer products, the pentasaccharide verbascose (Gal- $\alpha(1 \rightarrow 6)-G a l-\alpha(1 \rightarrow 6)-G a l-\alpha(1 \rightarrow 6)$ Glc- $\alpha(1 \leftrightarrow 2) \beta$-Fru) was the main oligosaccharide synthesized under the mechanism described in previous sections. The maximum formation $\left(68.5 \mathrm{~g} \mathrm{~L}^{-1}\right)$ was observed at $6 \mathrm{~h}$ of enzymatic reaction and comprised $84 \%$ of the total synthesized $\alpha$-GOS (Fig. 7b). As in the case of raffinose, three additional minor products, i.e. $\alpha$-1,6-galactotriose, $\alpha$-1,6-galactobiose and the same unknown trisaccharide detected during the synthesis of raffinose, were also found and quantified.

Finally, by increasing the concentration of starting stachyose from 200 to $400 \mathrm{~g} \mathrm{~L}^{1} \mathrm{a} \sim 3$-fold increase of either verbascose or total $\alpha$-GOS was found, shortening the reaction time needed to reach the maximum levels, as well as yielding up to $20.7 \%$ of total $\alpha$-GOS (Table 1 ).

\subsubsection{Synthesis of $\alpha$-GOS from AlphaGOS ${ }^{\circledast}$}

The use of $\mathrm{AlphaGOS}^{\circledast}$ at $400 \mathrm{~g} \mathrm{~L}^{-1}$ also demonstrated the ability of manninotriose and verbascotetraose to act as galactosyl donors by considering their respective hydrolysis degree of $83.7 \%$ and $77.9 \%$ after $24 \mathrm{~h}$ of enzymatic reaction. Thus, the monosaccharides glucose and galactose were the most abundant carbohydrates at the end of the reaction (Fig. 8a). Remarkably, the notable presence of the uncommon verbascopentaose[Instruction: In pdf version in 3.3.5. section line 7:

common verbascopentaose

appear occupying the entire line

Is it possible to fill in this line with more words??] (Gal- $\alpha(1 \rightarrow 6)-G a l-\alpha(1 \rightarrow 6)-G a l-\alpha(1 \rightarrow 6)-G a l-\alpha(1 \rightarrow 6)$ Glc), whose maximum formation (42.6 $\mathrm{g} \mathrm{L}^{-1}$ ) was observed at $8 \mathrm{~h}$ of enzymatic reaction (Fig. $8 \mathrm{~b}$ ), revealed the ability of verbascotetraose, which comprised $\sim 43449.5 \%$ of the composition of the commercial $\mathrm{AlphaGOS}^{\circledR}$, to act as a galactosyl-acceptor with good efficiency. In addition, the presence of verbascopentaose was already detected by GC-FID when AlphaGOS ${ }^{\circledR}$ was used as starting substrate at $200 \mathrm{~g} \mathrm{~L}^{-1}$ (peak 13 in Fig. 4d). As in previous sections, the content of $\alpha$-1,6-galactobiose was steadily increased until the end of the reaction, likely due to the hydrolysis of $\alpha$-GOS of higher degree of polymerization (Fig. 8b). Finally, both the maximum concentration and the yield in total $\alpha$-GOS were greatly enhanced by increasing the initial concentration of AlphaGOS $^{\circledR}$ from 200 to $400 \mathrm{~g} \mathrm{~L}^{-1}$ (Table 1). 

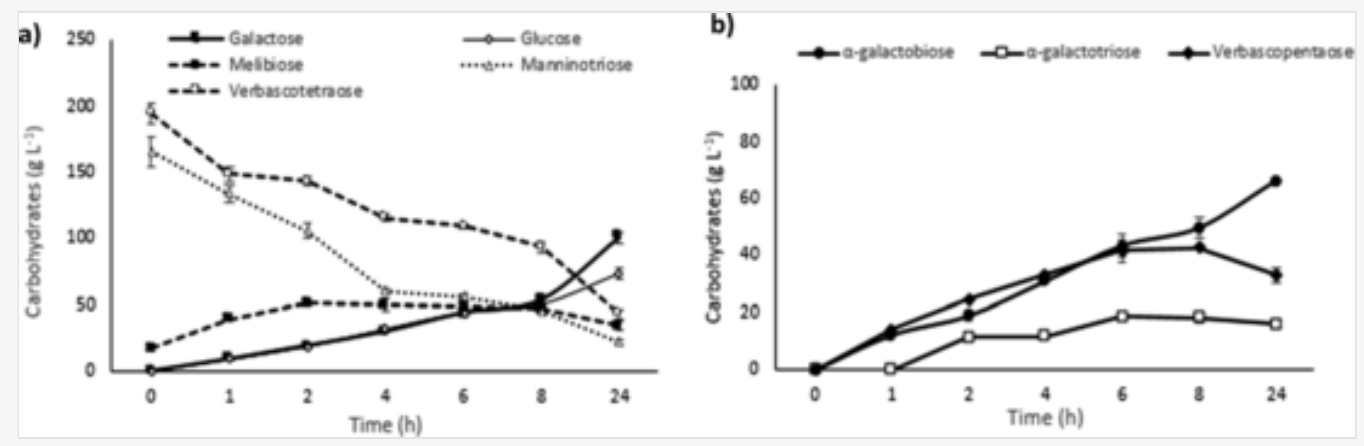

Concentration of monosaccharides and $\operatorname{AlphaGOS}^{\circledR}$ (a) and formed $\alpha$-galactooligosaccharides (b) upon transgalactosylation reaction catalyzed by Lactobacillus plantarum WCFS1 MelA $\alpha$-galactosidase using AlphaGOS ${ }^{\circledR}$ at $400 \mathrm{~g} \mathrm{~L}^{-1}$ as starting substrate. Vertical errors represented standard deviations $(n=3)$.

\section{Conclusions}

To the best of our knowledge, this work describes, for the first time, the biochemical characterization of MelA $\alpha$-D-galactosidase from Lactobacillus plantarum WCFS1. An efficient hydrolysis of RFOS, such as raffinose and stachyose, was achieved, with a degradation degree greater than $84 \%$, revealing that L. plantarum MelA has a high capacity to hydrolyze non-digestible RFOS. Likewise, MelA $\alpha$-galactosidase showed a high regioselectivity, efficiency and great diversity in accommodating donor and acceptor substrates for the synthesis of $\alpha$-GOS through transgalactosylation reactions. Thus, the enzyme exhibited a great preference for the transfer of galactosyl residues to the C6-hydroxyl group of galactose units to elongate the chain of $\alpha$-GOS having either a terminal sucrose (i.e., RFOS) or a terminal glucose (melibiose, manninotriose and verbascotetraose). Under optimum $\mathrm{pH}$, temperature and enzyme and starting substrate concentrations, the maximum yield in total $\alpha$-GOS ranged from $20.7 \%$ (using stachyose as donor and acceptor substrate) to $38.0 \%$ (using melibiose as starting substrate). To conclude, our findings indicate the feasibility of using MelA from Lactobacillus plantarum WCFS1 in the hydrolysis of RFOS and in the efficient and versatile synthesis of $\alpha$ GOS with appealing functional properties in the context of food and nutraceutical applications. Likewise, our results open up interesting possibilities for the further development of novel hetero- $\alpha$-galactooligosaccharides using specific $\alpha$-GOS compounds as donors and different acceptors to design new oligosaccharides exerting promising bioactive properties.

\section{Acknowledgements}

This work has been financed by the Spanish Ministries of Economy, Industry and Competitiveness (Projects AGL2017-84614-C2-1-R and AGL2017-84614-C2-2-R) and Science, Innovation and Universities (Project RTI2018-101273-J-I00). Paloma Delgado-Fernández thanks to Ministry of Science, Innovation and Universities of Spain for providing FPI predoctoral fellowship. We thank Sandra Martin for her participation on the cloning and characterization of L. plantarum MelA.

\section{Declaration of competing interest}


The authors declare that there are no conflicts of interest.

\section{Appendix A Supplementary data}

Supplementary data to this article can be found online at https://doi.org/10.1016/j.ijbiomac.2019.10.237.

\section{References}

[1] C. Ganter, A. Böck, P. Buckel, R. Mattes, Production of thermostable, recombinant $\alpha-$ galactosidase suitable for raffinose elimination from sugar beet syrup, J. Biotechnol. 8 (4) (1988) 301-310, doi:10.1016/0168-1656(88)90022-3.

[2] R.J. Desnick, Enzyme replacement therapy for Fabry disease: lessons from two $\alpha$-galactosidase A orphan products and one FDA approval, Expert Opin. Biolog. Th. 4 (7) (2004) 1167-1176, doi:10.1517/14712598.4.7.1167.

[3] M.L. Olsson, H. Clausen, Modifying the red cell surface: towards an ABO-universal blood supply, Br. J. Haematol. 140 (1) (2008) 3-12, doi:10.1111/j.1365-2141.2007.06839.x.

[4] P. Spangenberg, C. André, M. Dion, C. Rabiller, R. Mattes, Comparative study of new $\alpha$ galactosidases in transglycosylation reactions, Carbohyd. Res. 329 (2000) 65-73, doi:10.1016/S0008-6215(00)00170-1.

[5] H. Wang, R. Ma, P. Shi, X. Xue, H. Luo, H. Huang, Y. Bai, P. Yang, B. Yao, A new $\alpha-$ galactosidase from thermoacidophilic Alicyclobacillus sp. A4 with wide acceptor specificity for transglycosylation, Appl. Biochem. Biotechnol. 174 (2014) 328-338, doi:10.1007/s12010-0141050-8.

[6] O. Hernandez-Hernandez, A. Olano, R. Rastall, F.J. Moreno, In vitro digestibility of dietary carbohydrates: toward a standardized methodology beyond amylolytic and microbial enzymes, Front. Nutr. 6 (2019) 61, doi:10.3389/fnut.2019.00061.

[7] Y. Wang, B.A. Black, J.M. Curtis, M.G. Ganzle, Characterization of $\alpha$-galacto-oligosaccharides formed via heterologous expression of $\alpha$-galactosidases from Lactobacillus reuteri in Lactococcus lactis, App. Microbiol. Biotechnol. 98 (6) (2014) 2507-2517, doi:10.1007/s00253013-5145-x.

[8] Z. Dai, W. Lyu, X. Xiang, Y. Tang, B. Hu, S. Ou, X. Zeng, Immunomodulatory Effects of enzymatic-synthesized $\alpha$-galactooligosaccharides and evaluation of the structure-activity relationship, J. Agric. Food Chem. 66 (34) (2018) 9070-9079, doi:10.1021/acs.jafc.8b01939. 
[9] C.E. Rycroft, M.R. Jones, G.R. Gibson, R.A. Rastall, A comparative in vitro evaluation of the fermentation properties of prebiotic oligosaccharides, J. Appl. Microbiol. 91 (5) (2001) 878-887, doi:10.1046/j.1365-2672.2001.01446.x.

[10] O. Hernandez-Hernandez, G.L. Côté, S. Kolida, R.A. Rastall, M.L. Sanz, In vitro fermentation of alternansucrase raffinose-derived oligosaccharides by human gut bacteria, J. Agric. Food Chem. 59 (2011) 10901-10906, doi:10.1021/jf202466s.

[11] P. Gulewicz, S. Szymaniec, B. Bubak, J. Frias, C. Vidal-Valverde, K. Trojanowska, K. Gulewicz, Biological activity of $\alpha$-galactoside preparations from Lupinus angustifolius L. and Pisum sativum L, Seeds. J. Agric. Food Chem. 50 (2) (2002) 384-389, doi:10.1021/jf010973y.

[12] Z. Dai, W. Lyu, M. Xie, Q. Yuan, H. Ye, B. Hu, X. Zeng, et al., Effects of $\alpha-$ galactooligosaccharides from chickpeas on high-fat-diet-induced metabolic syndrome in mice. J. Agric. Food Chem. 65(15) (2017) 3160-3166, doi:10.1021/acs.jafc.7b00489.

[13] M.H. Bang, O.S. Chio, W.K. Kim, Soyoligosaccharide increases fecal Bifidobacteria counts, short-chain fatty acids, and fecal lipid concentrations in young korean women, J. Med. Food. 10 (2) (2007) 366-370, doi:10.1089/jmf.2005.096.

[14] F.B. Morel, Q. Dai, J. Ni, D. Thomas, P. Parnet, P. Fança-Berthon, $\alpha$-Galacto-oligosaccharides dose-dependently reduce appetite and decrease inflammation in overweight adults, J. Nutr. 145 (9) (2015) 2052-2059, doi:10.3945/jn.114.204909.

[15] C. Martinez-Villaluenga, J. Frias, C. Vidal-Valverde, Alpha-galactosides: antinutritional factors or functional ingredients?, Crit. Rev. Food Sci. Nutr. 48 (4) (2008) 301-316, doi:10.1080/10408390701326243.

[16] C. Liu, H. Ruan, H. Shen, Q. Chen, B. Zhou, Y. Li, G. He, Optimization of the fermentation medium for alpha-galactosidase production from Aspergillus foetidus ZU-G1 using response surface methodology, J. Food Sci. 72 (4) (2007) 120-125, doi:10.1111/j.17503841.2007.00328.x.

[17] Y. Huang, H. Zhang, P. Ben, Y. Duan, M. Lu, Z. Li, Z. Cui, Characterization of a novel GH36 $\alpha$ galactosidase from Bacillus megaterium and its application in degradation of raffinose family oligosaccharides, Int. J. Biolog. Macromol. $108 \quad$ (2018) 98-104, doi:10.1016/j.ijbiomac.2017.11.154.

[18] J.M. Jang, Y. Yang, R. Wang, H. Bao, H. Yuan, J. Yang, Characterization of a high performance $\alpha$-galactosidase from Irpex lacteus and its usage in removal of raffinose family oligosaccharides from soymilk, Int. J. Biolog. Macromol. $131 \quad$ (2019) 1138-1146, doi:10.1016/j.ijbiomac.2019.04.060.

[19] W. Shen, Y. Li, H. Chen, Z. Jin, X. Xu, J. Zhao, Z. Xie, Purification and application of $\alpha-$ galactosidase from germinating coffee beans (Coffea arabica), Eur. Food Res. Technol. 228 (6) 
(2009) 969, doi:10.1007/s00217-009-1013-4.

[20] Y. Cao, T. Yuan, P. Shi, H. Luo, N. Li, K. Meng, B. Yao, Properties of a novel $\alpha$-galactosidase from Streptomyces sp. S27 and its potential for soybean processing, Enzyme Microb. Technol. 47 (7) (2010) 305-312, doi:10.1016/j.enzmictec.2010.09.007.

[21] J.S. Teixeira, V. McNeill, M.G. Gänzle, Levansucrase and sucrose phoshorylase contribute to raffinose, stachyose, and verbascose metabolism by lactobacilli, Food Microbiol. 31 (2) (2012) 278-284, doi:10.1016/j.fm.2012.03.003.

[22] P. Katrolia, E. Rajashekhara, Q. Yan, Z. Jiang, Biotechnological potential of microbial $\alpha-$ galactosidases, Crit. Rev. Biotechnol. $34 \quad$ (4) (2013) 307-317, doi:10.3109/07388551.2013.794124.

[23] A.N. Roopashri, M.C. Varadaraj, Hydrolysis of flatulence causing oligosaccharides by $\alpha$-Dgalactosidase of a probiotic Lactobacillus plantarum MTCC 5422 in selected legume flours and elaboration of probiotic attributes in soy-based fermented product, Eur. Food Res. Technol. 239 (1) (2014) 99-115, doi:10.1007/s00217-014-2207-y.

[24] G. Tzortzis, A.J. Jay, M.L.A. Baillon, G.R. Gibson, R.A. Rastall, Synthesis of $\alpha$ galactooligosaccharides with $\alpha$-galactosidase from Lactobacillus reuteri of canine origin, App. Microbiol. Biotechnol. 63 (3) (2003) 286-292, doi:10.1007/s00253-003-1426-0.

[25] M. Kleerebezem, J.Boekhorst, R. van Kranenburg, D. Molenaar, O.P. Kuipers, R. Leer, R.J. Siezen, et al., Complete genome sequence of Lactobacillus plantarum WCFS1. Proc. Natl. Acad. Sci. U.S.A. 100(4) (2003) 1990-1995, doi:10.1073/pnas.0337704100.

[26] M.C. de Vries, E.E. Vaughan, M. Kleerebezem, W.M. de Vos, Lactobacillus plantarumsurvival, functional and potential probiotic properties in the human intestinal tract, Int. Dairy J. 16 (9) (2006) 1018-1028, doi:10.1016/j.idairyj.2005.09.003.

[27] F. Bringel, P. Quénée, P. Tailliez, Polyphasic investigation of the diversity within Lactobacillus plantarum related strains revealed two L. plantarum subgroups, Syst. Appl. Microbiol. 24 (4) (2001) 561-571, doi:10.1078/0723-2020-00061.

[28] A. Silvestroni, C. Connes, F. Sesma, G.S. de Giori, J.C. Piard, Characterization of the melA locus for $\alpha$-galactosidase in Lactobacillus plantarum, Appl. Environ. Microbiol. 68 (11) (2002) 54645471, doi:10.1128/AEM.68.11.5464-5471.2002.

[29] J.M. Lambert, R.S. Bongers, M. Kleerebezem, Cre-lox-based system for multiple gene deletions and selectable-marker removal in Lactobacillus plantarum. Appl. Environ. Microbiol. 73(4) (2007), doi:1126-1135, 10.1128/AEM.01473-06.

[30] J.M. Landete, J.A. Curiel, H. Rodríguez, B. de las Rivas, R. Muñoz, Aryl glycosidases from Lactobacillus plantarum increase antioxidant activity of phenolic compounds. J. Funct. Foods. 7 
(2014) 322-329, doi:10.1016/j.jff.2014.01.028.

[31] G. Spano, A. Rinaldi, M. Ugliano, L. Moio, L. Beneduce, S. Massa, A $\beta$-glucosidase gene isolated from wine Lactobacillus plantarum is regulated by abiotic stresses, J. Appl. Microbiol. 98 (4) (2005) 855-861, doi:10.1111/j.1365-2672.2004.02521.x.

[32] I. Acebrón, J.A. Curiel, B. de las Rivas, R. Muñoz, J.M. Mancheño, Cloning, production, purification and preliminary crystallographic analysis of a glycosidase from the food lactic acid bacterium Lactobacillus plantarum CECT 748T. Protein Expr. Purif. 68(2) (2009) 177-182, doi:10.1016/j.pep.2009.07.006.

[33] B. Mayo, B. González, J.E. Suárez, P. Arca, Cloning and expression of the plasmid encoded $\beta$-Dgalactosidase gene from a Lactobacillus plantarum strain of dairy origin, FEMS Microbiol. Lett 122 (1-2) (1994) 145-151, doi:10.1111/j.1574-6968.1994.tb07157.x.

[34] M. Fernández, A. Margolles, J.E. Suárez, B. Mayo, Duplication of the $\beta$-galactosidase gene in some Lactobacillus plantarum strains, Int. J. Food Microbiol 48 (2) (1999) 113-123, doi:10.1016/S0168-1605(99)00031-8.

[35] D.M.A. Saulnier, D. Molenaar, W.M. de Vos, G.R. Gibson, S. Kolida, Identification of prebiotic fructooligosaccharide metabolism in Lactobacillus plantarum WCFS1 through microarrays, Appl. Environ. Microbiol. 73 (6) (2007) 1753-1765, doi:10.1128/AEM.01151-06.

[36] M. Ávila, M. Jaquet, D. Moine, T. Requena, C. Peláez, F. Arigoni, I. Jankovic, Physiological and biochemical characterization of the two $\alpha$-1-rhamnosidases of Lactobacillus plantarum NCC245. Microbiol. 155(8) (2009) 2739-2749, doi:10.1099/mic.0.027789-0.

[37] V. Lombard, H. Golaconda Ramulu, E. Drula, P.M. Coutinho, B. Henrissat, The carbohydrateactive enzymes database (CAZy) in 2013. Nucleic Acids Res. 42 (2014) 490-495, doi:10.1093/nar/gkt1178.

[38] M. Meijerink, S. van Hemert, N. Taverne, M. Wels, P. de Vos, P.A. Bron, H.F. Savelkoul, J. van Bilsen, M. Kleerebezem, J.M. Wells, Identification of genetic loci in Lactobacillus plantarum that modulate the immune response of dentritic cells using comparative genome hybridization. PLoS One, 5 (2010) e10632, https://doi: 10.1371/journal.pone.0010632.

[39] J.A. Curiel, B. de las Rivas, J.M. Mancheño, R. Muñoz, The pURI family of expression vectors: A versatile set of ligation independent cloning plasmids for producing recombinant His-fusion proteins. Protein Expr. Purif. 76 (2011) 44-53, doi:10.1016/j.pep.2010.10.013.

[40] M.L. Sanz, M. Villamiel, I. Martínez-Castro, Inositols and carbohydrates in different fresh fruit juices. Food $\quad$ Chem. $\quad$ 87(3) 325-328, https://doi.org/https://doi.org/10.1016/j.foodchem.2003.12.001. 
M.G. Gänzle, R. Follador, Metabolism of oligosaccharides and starch in lactobacilli: a review, Front. Microbiol. 3 (2012) 340, doi:10.3389/fmicb.2012.00340.

[42] B.K. Mital, R.S. Shallenberger, K.H. Steinkraus, a-Galactosidase activity of lactobacilli, Appl. Microbiol. 26 (1973) 783-788.

[43] C. Tamura, O. Matsushita, Melibiose transport system in Lactobacillus plantarum, Microbiol. Immunol. 36 (1992) 1119-1128, doi:10.1111/j.1348-0421.1992.tb02116.x.

[44] M.S. Garro, G.S. de Giori, G.F. de Valdez, G. Oliver, Characterization of alpha-galactosidase from Lactobacillus fermentum, J. Appl. Bacteriol. 75 (1993) 485-488, doi:10.1111/j.13652672.1993.tb02805.x.

[45] J. Coombs, J.E. Brenchley, Characterization of two new glycosyl hydrolases from the lactic acid bacterium Carnobacterium piscicola Strain BA, Appl. Environ. Microbiol. 67 (2001) 5094-5099, doi:10.1128/AEM.67.11.5094-5099.2001.

[46] M. Yoon, H. Hwang, Reduction of soybean oligosaccharides and properties of $\alpha$-D-galactosidase from Lactobacillus curvatus R08 and Leuconostoc mesenteroides JK55, Food Microbiol. 25 (2008) 815-823, doi:10.1016/j.fm.2008.04.008.

[47] E.A. Carrera-Silva, A. Silvestroni, J.G. LeBlanc, J.C. Piard, G.S. de Giori, F. Sesma, A Thermostable $\alpha$-galactosidase from Lactobacillus fermentum CRL722: Genetic characterization and main properties, Curr. Microbiol. 53 (2006) 374-378, doi:10.1007/s00284-005-0442-y.

[48] S.A. Ibrahim, A.Y. Alazzeh, S.S. Awaisheh, D. Song, A. Shahbazi, A.A. AbuGhazaleh, Enhancement of $\alpha$ - and $\beta$-galactosidase activity in Lactobacillus reuteri by different metal ions, Biol. Trace Elem. Research. 136 (2010) 106-116, doi:10.1007/s12011-009-8519-2.

[49] D. Otzen, Protein-surfactant interactions: A tale of many states, Biochim. Biophys. Acta 2011 (1814) 562-591, doi:10.1016/j.bbapap.2011.03.003.

[50] M.M. Gote, M.I. Khan, D.V. Gokhale, K.B. Bastawde, J.M. Khire, Purification, characterization and substrate specificity of thermostable $\alpha$-galactosidase from Bacillus stearothermophilus (NCIM-5146), Process Biochem. 41 (2006) 1311-1317, doi:10.1016/j.procbio.2006.01.003.

[51] M. Canedo, M. Jimenez-Estrada, J. Cassani, A. López-Munguía, Production of maltosylfructose (erlose) with levansucrase from Bacillus subtilis, Biocatal. Biotransfor. 16 (6) (1999) 475-485, doi:10.3109/10242429909015223.

[52] M. Diez-Municio, M. Herrero, B. de Las Rivas, R. Munoz, M.L. Jimeno, F.J. Moreno, Synthesis and structural characterization of raffinosyl-oligofructosides upon transfructosylation by Lactobacillus gasseri DSM 20604 inulosucrase, Appl. Microbiol. Biotechnol. 100 (14) (2016) 6251-6263, doi:10.1007/s00253-016-7405-z. 
A. Yamashita, H. Hashimoto, K. Fujita, M. Okada, S. Mori, S. Kitahata, Reverse reaction of Aspergillus niger APC-9319 $\alpha$-galactosidase in a supersaturated substrate solution: production of $\alpha$-linked galactooligosaccharide ( $\alpha$-GOS), Biosci. Biotech. Bioch. 69 (7) (2005) 1381-1388, doi:10.1271/bbb.69.1381.

\section{Appendix A Supplementary data}

The following are the Supplementary data to this article:

Multimedia Component 1

Supplementary Data 1

\section{Queries and Answers}

Query: Your article is registered as a regular item and is being processed for inclusion in a regular issue of the journal. If this is NOT correct and your article belongs to a Special Issue/Collection please contact c.abinesh@elsevier.com immediately prior to returning your corrections.

Answer: Yes

Query: The author names have been tagged as given names and surnames (surnames are highlighted in teal color). Please confirm if they have been identified correctly.

Answer: Yes 